Revue internationale de l'économie sociale

Recma

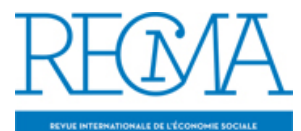

\title{
Pierre Lacour (1910-2006)
}

\section{André Chomel}

Numéro 302, novembre 2006

URI : https://id.erudit.org/iderudit/1021553ar

DOI : https://doi.org/10.7202/1021553ar

Aller au sommaire du numéro

\section{Éditeur(s)}

Association Recma

\section{ISSN}

1626-1682 (imprimé)

2261-2599 (numérique)

Découvrir la revue

\section{Citer ce document}

Chomel, A. (2006). Pierre Lacour (1910-2006). Revue internationale de l'économie sociale, (302), 5-6. https://doi.org/10.7202/1021553ar d'utilisation que vous pouvez consulter en ligne.

https://apropos.erudit.org/fr/usagers/politique-dutilisation/ 


\section{PIERRE LACOUR \\ (1910-2006)}

$\mathrm{P}$ ierre Lacour est décédé en avril dernier. C'est une grande figure de l'histoire coopérative qui disparaît avec lui. Il a joué un rôle majeur entre 1938 et 1975 dans le développement de la coopération, préparant, au tournant des années 70, l'émergence de l'économie sociale. Polytechnique, Science-Po, la Banque de France, le centre X-Crise, conseil financier de la CGT, tels sont quelques jalons d'un premier parcours au terme duquel P. Lacour est nommé, à 28 ans, à la direction de la Caisse centrale de Crédit coopératif. Celle-ci vient d'être crée par un décret du 31 octobre 1938; avec le recul de ce qui suivra, il en apparaittra comme le véritable fondateur.

Passé par Vichy pendant la guerre, avant de rejoindre la Résistance et les FTP, il sera rapporteur au conseil économique du Conseil national de la Résistance et, pour un temps, membre du Parti communiste et du bureau d'études économiques de la CGT. Par la suite, tout son parcours sera ordonné au développement de la « $4 \mathrm{C}$ » et de la coopération.

Visionnaire parfois isolé, il comprend très tôt au lendemain de la guerre, comme François Perroux, que l'évolution économique et sociale va requérir des initiatives d' "invention de structures " pour répondre à des besoins négligés par le marché ou l'Etat. C'est tout un champ qui lui parait dès lors s'ouvrir à la coopération.

Mais sa « $4 \mathrm{C}$ » est alors corsetée par des textes limitant rigoureusement sa compétence; les décennies 50 et 60 vont être consacrées, par une stratégie à longue portée, à l'ouverture du champ coopératif et corrélativement à l'extension de la compétence de la caisse: coopération maritime, logement social, commerçants détaillants..., puis nouvelles formes déclinées par le Centre pour le développement de la coopération (Cedecoop), créé à cet effet. Pierre Lacour s'attache particulièrement au mouvement coopératif de la pêche artisanale, groupée à son initiative dans la Confédération des organismes de crédit maritime mutuel, qu'il préside de 1956 à 1975. Cet engagement personnel l'amènera à présider également le comité des pêches à l'ACI et celui de la FAO.

Ces développements contribuent à une prise de conscience de l'unité du secteur coopératif. S'ensuit, largement grâce à l'initiative de Pierre Lacour, la création du Groupement national de la coopération en 1968. La bibliographie de Pierre Lacour est succincte; il n'a en effet guère commenté par écrit la genèse de cette aventure courant sur un tiers de siècle. Qu'il fut cependant un homme de pensée est attesté par son accompagnement de chercheurs comme Henri Desroche et Claude Vienney, pour 
lesquels il sera un appui précieux: leur coopération sera féconde, notamment pour les ouvertures qui s'en dégageront vers le concept d'économie sociale.

La fin du parcours de Pierre Lacour n'ira pas sans difficulté, entre autres à la suite de l'absorption de la Banque des sociétés ouvrières de production dont il fera le pari audacieux que lui parait commander l'avenir du Crédit coopératif.

Un tiers de siècle plus tard, le paysage de l'économie sociale est profondément transformé; il s'inscrit cependant bien dans la vision du futur qu'avait Pierre Lacour. La mémoire de sa créativité est un actif qui ne pouvait pas être livré à l'oubli du temps qui passe, non plus que, pour ceux qui l'ont connu, le souvenir de sa personnalité vigoureuse, inclassable, incommode, mais attachante et chaleureuse.

La Recma lui devait de se joindre à l'hommage qui fut rendu à Pierre Lacour lors de ses obsèques par le président Detilleux au nom du Crédit coopératif. 